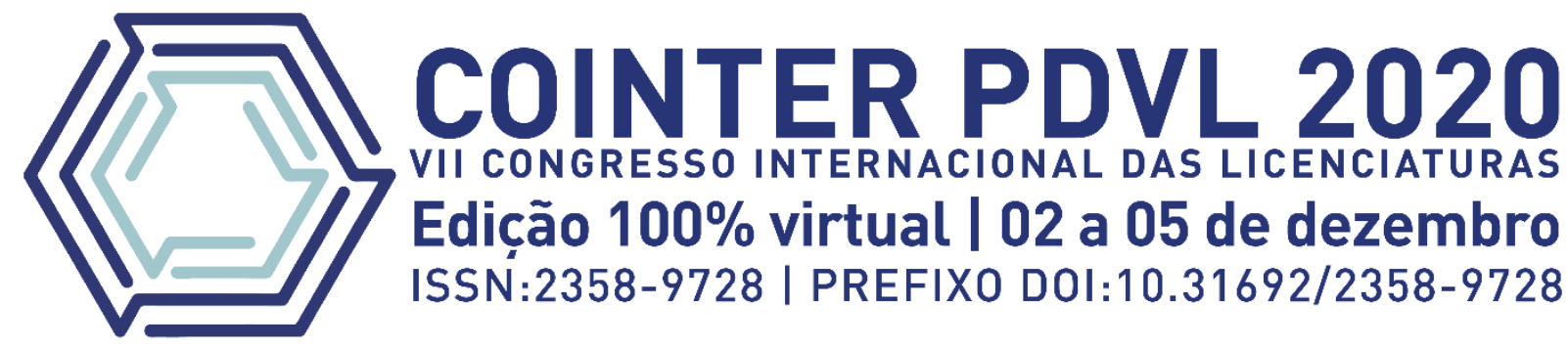

\title{
STEAMPUNK: UM ESTUDO SOBRE AS ARTES VISUAIS E SUAS INFLUENCIAS NAS NARRATIVAS LITERÁRIAS E AUDIOVISUAIS
}

\author{
STEAMPUNK: UN ESTUDIO SOBRE LAS ARTES VISUALES Y SUS \\ INFLUENCIAS EN LAS NARRATIVAS LITERARIAS Y AUDIOVISUALES
STEAMPUNK: A STUDY ABOUT VISUAL ARTS AND ITS INFLUENCES IN LITERARY AND AUDIOVISUAL NARRATIVES

\author{
Apresentação: Comunicação Oral
}

João Paulo Hergesel ${ }^{1}$

DOI: $\underline{\text { https://doi.org/10.31692/2358-9728.VIICOINTERPDVL.0457 }}$

\begin{abstract}
RESUMO
O Steampunk é um movimento cultural que ganhou evidência e definição a partir dos anos 1980, sendo considerado um subgênero da ficção científica e presente em variadas obras de artes, influenciando, ainda, novas narrativas na literatura e no cinema. Também denominado, no Brasil, como Vapor Punk ou Tecnavapor, o estilo ficou marcado por seu visual retrofuturista, isto é, que resgata aspectos do passado, mas adiciona tendências do futuro. Baseando-se nisso, este artigo surgiu com o objetivo de analisar criticamente os trabalhos mais relevantes já publicados em língua portuguesa sobre o referido estilo artístico-cultural. Buscou-se estudar as origens desse movimento, suas características e influências nas artes literárias e cinematográficas, a partir do questionamento: como compreender o Steampunk? O percurso metodológico envolveu uma abordagem quantiqualitativa, suportada pela revisão sistemática, realizada em 25 de setembro de 2020, tendo como base de pesquisa o Google Acadêmico. A fundamentação teórica, nesse sentido, envolveu estudos interdisciplinares contemporâneos sobre métodos de pesquisa exploratória e bibliográfica. Como resultado, observamos que a produção acadêmica brasileira destinada ao tema parece se concentrar em dois autores principais: Everly Pegoraro e Mônica Rebecca Ferrari Nunes - esta, também em coautoria de Marcos Antônio Bin. A leitura desses trabalhos nos auxiliou a entender o que é o gênero, suas origens e como ele pode influenciar as artes literárias e cinematográficas. Vimos que o Steampunk é um movimento cultural que une alguns aspectos do passado, sobretudo nas vestimentas e nos acessórios, com elementos futurísticos, como invenções e aparatos tecnológicos. Tal movimento teve origem na ficção científica, em subgêneros como o cyberpunk e em períodos como a Era Dourada, entre 1930 e 1950, e a Nova Onda, nos anos 1970 e 1980, propagando um embate na relação entre humano e máquina. Compreendemos que o Steampunk dependeu da arte literária para se propagar, sobretudo nas obras de Júlio Verne e de H. G. A. Wells, sendo consolidado nos livros Morlock Night e Infernal Devices, de Kevin Wayne Jeter. No contemporâneo, as características do Steampunk prevalecem na literatura, mas também alcançou outras artes, como a pintura, a ilustração e o cinema, e as mídias, como os games, a televisão e a internet.
\end{abstract}

Palavras-Chave: Artes visuais, Steampunk, Revisão sistemática.

\footnotetext{
${ }^{1}$ Professor permanente do Programa de Pós-Graduação em Linguagens, Mídia e Arte da Pontifícia Universidade Católica de Campinas (PUC-Campinas). Doutor em Comunicação (UAM), mestre em Comunicação e Cultura (Uniso) e licenciado em Letras (Uniso). Membro do grupo de pesquisa Entre(dis)cursos: sujeito e língua(gens). Contato: joao.hergesel@ puc-campinas.edu.br.
} 


\title{
RESUMEN
}

Steampunk es un movimiento cultural que ha ganado evidencia y definición desde la década de 1980, siendo considerado un subgénero de la ciencia ficción y presente en diversas obras de arte, influyendo, sin embargo, en las nuevas narrativas de la literatura y el cine. También llamado, en Brasil, como Vapor Punk o Tecnavapor, el estilo estuvo marcado por su mirada retro-futurista, es decir, que rescata aspectos del pasado, pero agrega tendencias de futuro. En base a esto, este artículo apareció con el objetivo de analizar críticamente los trabajos más relevantes ya publicados en portugués sobre el referido estilo artístico-cultural. Buscamos estudiar los orígenes de este movimiento, sus características e influencias en las artes literarias y cinematográficas, a partir de la pregunta: ¿cómo entender el Steampunk? La ruta metodológica involucró un enfoque cuantitativo y cualitativo, apoyado en la revisión sistemática, realizada el 25 de septiembre de 2020, con base en la búsqueda de Google Scholar. El fundamento teórico, en este sentido, involucró estudios interdisciplinarios contemporáneos sobre métodos de investigación exploratoria y bibliográfica. Como resultado, guiada por la revisión sistemática, observamos que la producción académica brasileña orientada al tema parece concentrarse en dos autores principales: Everly Pegoraro y Mônica Rebecca Ferrari Nunes - éste, también en coautoría con Marcos Antônio Bin. La lectura de estas obras nos ayudó a comprender qué es el género, sus orígenes y cómo puede influir en las artes literarias y cinematográficas. Hemos visto que Steampunk es un movimiento cultural que une algunos aspectos del pasado, especialmente en ropa y accesorios, con elementos futuristas, como inventos y dispositivos tecnológicos. Este movimiento se originó en la ciencia ficción, en subgéneros como el cyberpunk y en periodos como el Siglo de Oro, entre 1930 y 1950, y Nova Onda, en las décadas de 1970 y 1980, propagando un conflicto en la relación entre humano y máquina. Entendemos que Steampunk dependió del arte literario para difundirse, especialmente en las obras de Julio Verne y de H. G. A. Wells, siendo consolidado en los libros Morlock Night e Infernal Devices, de Kevin Wayne Jeter. En lo contemporáneo, las características del Steampunk prevalecen en la literatura, pero también alcanzó otras artes, como la pintura, la ilustración y el cine, y los medios de comunicación, como los juegos electrónicos, la televisión e internet.

Palabras Clave: Artes visuales, Steampunk, Revisión sistemática.

\begin{abstract}
Steampunk is a cultural movement that has gained evidence and definition since the 1980s, being considered a subgenre of science fiction and present in various works of art, influencing yet new narratives in literature and cinema. Also called, in Brazil, as Vapor Punk or Tecnavapor, the style was marked by its retro-futuristic look, that is, that rescues aspects of the past, but adds future trends. Based on this, this article appeared with the objective of critically analyzing the most relevant works already published in Portuguese on the referred artistic-cultural style. We sought to study the origins of this movement, its characteristics and influences in the literary and cinematographic arts, from the question: how to understand Steampunk? The methodological path involved a quantitative and qualitative approach, supported by the systematic review, carried out on September 25, 2020, based on the Google Scholar search. The theoretical foundation, in this sense, involved contemporary interdisciplinary studies on exploratory and bibliographic research methods. As a result, we observed that the Brazilian academic production aimed at the theme seems to be concentrated in two main authors: Everly Pegoraro and Mônica Rebecca Ferrari Nunes - this one, also co-authored by Marcos Antônio Bin. Reading these works helped us to understand what the genre is, its origins and how it can influence the literary and cinematographic arts. We have seen that Steampunk is a cultural movement that unites some aspects of the past, especially in clothing and accessories, with futuristic elements, such as inventions and technological devices. This movement originated in science fiction, in subgenres such as cyberpunk and in periods such as the Golden Age, between 1930 and 1950, and New Wave, in the 1970s and 1980s, propagating a conflict in the relationship between human and machine. We understand that Steampunk depended on literary art to spread, especially in the works by Julio Verne and by H. G. A. Wells, being consolidated in the books Morlock Night and Infernal Devices, by Kevin Wayne Jeter. In the contemporary, Steampunk's characteristics prevail in literature, but it also reached other arts, such as painting, illustration and cinema, and the media, such as games, television and the internet.
\end{abstract}

Keywords: Visual arts, Steampunk, Systematic review. 


\section{INTRODUÇÃO}

O Steampunk é um movimento cultural que ganhou evidência e definição a partir dos anos 1980, sendo considerado um subgênero da ficção científica e presente em variadas obras de artes, influenciando, ainda, novas narrativas na literatura e no cinema. Também denominado, no Brasil, como Vapor Punk ou Tecnavapor, o estilo ficou marcado por seu visual retrofuturista, isto é, que resgata aspectos do passado, mas adiciona tendências do futuro.

Baseando-se nisso, este artigo surgiu com o objetivo de analisar criticamente os trabalhos mais relevantes já publicados em língua portuguesa sobre o referido estilo artísticocultural. Buscou-se estudar as origens desse movimento, suas características e influências nas artes literárias e cinematográficas, a partir do questionamento: como compreender o Steampunk?

O percurso metodológico envolveu uma abordagem quantiqualitativa, suportada pela revisão sistemática, realizada em 25 de setembro de 2020, tendo como base de pesquisa o Google Acadêmico (https://scholar.google.com/). A fundamentação teórica, nesse sentido, envolveu estudos interdisciplinares contemporâneos sobre métodos de pesquisa exploratória e bibliográfica.

A título de registro, este artigo é derivado do trabalho de conclusão de curso apresentado para obtenção do título de Licenciado em Artes Visuais do Grupo IBRA Educacional, em parceria com o Centro Universitário ETEP. Em complementação, o levantamento bibliográfico realizado colabora com o projeto de pesquisa Arte e inovação na televisão brasileira, em desenvolvimento junto ao Programa de Pós-Graduação em Linguagens, Mídia e Arte da Pontifícia Universidade Católica de Campinas (PUC-Campinas).

\section{FUNDAMENTAÇÃO TEÓRICA}

As Artes Visuais, juntamente da Dança, da Música e do Teatro, compreendem as linguagens que integram o componente curricular Arte no Ensino Fundamental, de acordo com a Base Nacional Comum Curricular (BNCC, 2017). Acerca das Artes Visuais, exclusivamente, o documento esclarece:

As Artes visuais são os processos e produtos artísticos e culturais, nos diversos tempos históricos e contextos sociais, que têm a expressão visual como elemento de comunicação. Essas manifestações resultam de explorações plurais e transformações de materiais, de recursos tecnológicos e de apropriações da cultura cotidiana.

As Artes visuais possibilitam aos alunos explorar múltiplas culturas visuais, dialogar com as diferenças e conhecer outros espaços e possibilidades 
inventivas e expressivas, de modo a ampliar os limites escolares e criar novas formas de interação artística e de produção cultural, sejam elas concretas, sejam elas simbólicas (BNCC, 2017, p. 195).

Ainda no espectro da Educação Básica, o componente Arte - e, portanto, a modalidade das Artes Visuais está inclusa - deve articular seis dimensões do conhecimento, classificadas como: criação, crítica, estesia, expressão, fruição e reflexão (BNCC, 2017).

A criação, de acordo com a BNCC (2017, p. 194), "refere-se ao fazer artístico, quando os sujeitos criam, produzem e constroem". Em outras palavras, corresponde a "uma atitude intencional e investigativa que confere materialidade estética a sentimentos, ideias, desejos e representações em processos, acontecimentos e produções artísticas individuais ou coletivas" (BNCC, 2017, p. 194). Tal dimensão "trata do apreender o que está em jogo durante o fazer artístico, processo permeado por tomadas de decisão, entraves, desafios, conflitos, negociações e inquietações" (BNCC, 2017, p. 194).

A crítica, segundo a BNCC (2017, p. 194), "refere-se às impressões que impulsionam os sujeitos em direção a novas compreensões do espaço em que vivem, com base no estabelecimento de relações". Essa relação ocorre "por meio do estudo e da pesquisa, entre as diversas experiências e manifestações artísticas e culturais vividas e conhecidas" (BNCC, 2017, p. 194). Em outras palavras, essa dimensão “articula ação e pensamento propositivos, envolvendo aspectos estéticos, políticos, históricos, filosóficos, sociais, econômicos e culturais (BNCC, 2017, p. 194).

A estesia, conforme a BNCC (2017, p. 194), "refere-se à experiência sensível dos sujeitos em relação ao espaço, ao tempo, ao som, à ação, às imagens, ao próprio corpo e aos diferentes materiais". Tal dimensão "articula a sensibilidade e a percepção, tomadas como forma de conhecer a si mesmo, o outro e o mundo" (BNCC, 2017, p. 194), isto é, "o corpo em sua totalidade (emoção, percepção, intuição, sensibilidade e intelecto) é o protagonista da experiência" (BNCC, 2017, p. 194).

A expressão, de acordo com a BNCC (2017, p. 194), "refere-se às possibilidades de exteriorizar e manifestar as criações subjetivas por meio de procedimentos artísticos, tanto em âmbito individual quanto coletivo". Ou seja, "essa dimensão emerge da experiência artística com os elementos constitutivos de cada linguagem, dos seus vocabulários específicos e das suas materialidades" (BNCC, 2017, p. 194).

A fruição, segundo a $\operatorname{BNCC}$ (2017, p. 195), "refere-se ao deleite, ao prazer, ao estranhamento e à abertura para se sensibilizar durante a participação em práticas artísticas e culturais”. Isto é, “essa dimensão implica disponibilidade dos sujeitos para a relação continuada 
com produções artísticas e culturais oriundas das mais diversas épocas, lugares e grupos sociais" (BNCC, 2017, p. 195).

A reflexão, por sua vez, "refere-se ao processo de construir argumentos e ponderações sobre as fruições, as experiências e os processos criativos, artísticos e culturais" (BNCC, 2017, p. 195). Ainda segundo a $\operatorname{BNCC}(2017$, p. 195), a reflexão consiste na "atitude de perceber, analisar e interpretar as manifestações artísticas e culturais, seja como criador, seja como leitor".

Diante de todas essas considerações, torna-se possível concluir que, em conformidade com a legislação atual, é preciso ter em evidência o caráter subjetivo, experiencial e vivencial da Arte, "uma vez que os conhecimentos e as experiências artísticas são constituídos por materialidades verbais e não verbais, sensíveis, corporais, visuais, plásticas e sonoras" (BNCC, 2017, p. 195).

Nos anos iniciais do Ensino Fundamental (do 1. ${ }^{\circ}$ ao 5. ${ }^{\circ}$ ano), as Artes Visuais estão ligadas a seis objetos de conhecimento, de acordo com a BNCC (2017), a saber: contextos e práticas; elementos da linguagem; matrizes estéticas e culturais; materialidades; processos de criação; e sistemas da linguagem. Cada segmento tem habilidades específicas a serem desenvolvidas.

Em contextos e práticas, espera-se "identificar e apreciar formas distintas das artes visuais tradicionais e contemporâneas, cultivando a percepção, o imaginário, a capacidade de simbolizar e o repertório imagético" (BNCC, 2017, p. 201). Em elementos da linguagem, fazse necessário "explorar e reconhecer elementos constitutivos das artes visuais (ponto, linha, forma, cor, espaço, movimento etc.)" (BNCC, 2017, p. 201).

Em matrizes estéticas e culturais, é preciso "reconhecer e analisar a influência de distintas matrizes estéticas e culturais das artes visuais nas manifestações artísticas das culturas locais, regionais e nacionais (BNCC, 2017, p. 201). Em materialidades, estima-se "experimentar diferentes formas de expressão artística (desenho, pintura, colagem, quadrinhos, dobradura, escultura, modelagem, instalação, vídeo, fotografia etc.)” (BNCC, 2017, p. 201), sobretudo se fizer "uso sustentável de materiais, instrumentos, recursos e técnicas convencionais e não convencionais” (BNCC, 2017, p. 201).

Em processos de criação, deve-se "experimentar a criação em artes visuais de modo individual, coletivo e colaborativo, explorando diferentes espaços da escola e da comunidade" (BNCC, 2017, p. 201), assim como “dialogar sobre a sua criação e as dos colegas, para alcançar sentidos plurais" (BNCC, 2017, p. 201). Em sistemas da linguagem, objetiva-se "reconhecer algumas categorias do sistema das artes visuais (museus, galerias, instituições, artistas, artesãos, curadores etc.)" (BNCC, 2017, p. 201). 


\section{STEAMPUNK: UM ESTUDO SOBRE AS ARTES VISUAIS E SUAS INFLUÊNCIAS}

Percebe-se, portanto, que, nos anos iniciais do Ensino Fundamental, o componente curricular Arte contribui para o desenvolvimento do aluno em seu processo de alfabetização e letramento. Em outras palavras, "ao possibilitar o acesso à leitura, à criação e à produção nas diversas linguagens artísticas, contribui para o desenvolvimento de habilidades relacionadas tanto à linguagem verbal quanto às linguagens não verbais” (BNCC, 2017, p. 199).

Já nos anos finais do Ensino Fundamental (do 6. ${ }^{\circ}$ ao 9..$^{\circ}$ ano), as Artes Visuais estão ligadas a cinco objetos de conhecimento, de acordo com a BNCC (2017), a saber: contextos e práticas; elementos da linguagem; materialidades; processos de criação; e sistemas da linguagem. Cada segmento tem habilidades específicas a serem desenvolvidas.

A contextos e práticas, cabe "pesquisar, apreciar e analisar formas distintas das artes visuais tradicionais e contemporâneas, em obras de artistas brasileiros e estrangeiros de diferentes épocas e em diferentes matrizes estéticas e culturais" (BNCC, 2017, p. 207), de maneira que se possa "ampliar a experiência com diferentes contextos e práticas artísticovisuais e cultivar a percepção, o imaginário, a capacidade de simbolizar e o repertório imagético" (BNCC, 2017, p. 207).

Dentro desse objeto de conhecimento, também se espera "pesquisar e analisar diferentes estilos visuais, contextualizando-os no tempo e no espaço" (BNCC, 2017, p. 207) e "analisar situações nas quais as linguagens das artes visuais se integram às linguagens audiovisuais (cinema, animações, vídeos etc.), gráficas (capas de livros, ilustrações de textos diversos etc.), cenográficas, coreográficas, musicais etc.” (BNCC, 2017, p. 207).

Em elementos da linguagem, visa-se a "analisar os elementos constitutivos das artes visuais (ponto, linha, forma, direção, cor, tom, escala, dimensão, espaço, movimento etc.) na apreciação de diferentes produções artísticas". Em materialidades, almeja-se "experimentar e analisar diferentes formas de expressão artística (desenho, pintura, colagem, quadrinhos, dobradura, escultura, modelagem, instalação, vídeo, fotografia, performance etc.)" (BNCC, 2017, p. 207).

Em processos de criação, objetiva-se "desenvolver processos de criação em artes visuais, com base em temas ou interesses artísticos, de modo individual, coletivo e colaborativo" (BNCC, 2017, p. 207), especialmente ao fazer "uso de materiais, instrumentos e recursos convencionais, alternativos e digitais" (BNCC, 2017, p. 207). Além disso, é preciso “dialogar com princípios conceituais, proposições temáticas, repertórios imagéticos e processos de criação nas suas produções visuais".

Já em sistemas da linguagem, deve-se "diferenciar as categorias de artista, artesão, produtor cultural, curador, designer, entre outras, estabelecendo relações entre os profissionais 
do sistema das artes visuais" (BNCC, 2017, p. 207). Com isso, conclui-se o resgate, em forma de enumeração, dos objetos de conhecimento e as respectivas habilidades que esperam despertar no educando.

Percebe-se, portanto, que, nos anos finais do Ensino Fundamental, o componente curricular Arte contribui para o aprofundamento do aluno em diversas linguagens, propondo experiências distintas. Além disso, espera-se que "no diálogo entre elas [as linguagens] e com as outras áreas do conhecimento -, com vistas a possibilitar aos estudantes maior autonomia nas experiências e vivências artísticas" (BNCC, 2017, p. 205).

Diante das discussões acerca da BNCC e da sugestão de integralizar as artes - não mais fatiando as manifestações artísticas em segmentos independentes, mas propondo um diálogo entre entras -, Pimentel e Magalhães (2018, p. 230) lançam o seguinte questionamento: “Precisamos resistir para existir ou é preciso reinventar o ensino/aprendizagem em Arte?". Para as autoras:

[...] a cada produção artística estamos criando pedagogia, ou seja, estamos criando arte e formas de aprender arte, mesmo que não se tenha consciência disso. Produzir arte, portanto, é uma ação de extrema responsabilidade para o Professor de Arte na Educação Básica, uma vez que, nas aulas, pelo fazer, fruir ou contextualizar arte, novas formas de vida e de aprendizagem são criadas, e atravessam a vida dos estudantes sob sua tutela (PIMENTEL; MAGALHÃES, 2018, p. 229).

Em diálogo com essa perspectiva de união e (trans)formação por meio das artes no processo educacional, Tolentino e Moreno (2019, p. 11) defendem que as variadas maneiras de produzir arte "possibilitam a construção de um espaço no qual as pessoas sejam respeitadas em suas individualidades culturais e estimuladas a compreender e concordar com as diferenças e a pluralidade de formas e existência". Os autores, porém, revelam uma fragilidade nas orientações da BNCC para as Artes:

O documento não trata das dificuldades do professor de arte, levando em consideração que esse profissional pode atuar a partir de muitas formações (Licenciatura em música, dança, teatro, artes visuais). Além de não esclarecer os objetivos de aprendizagem de forma clara, dificultando a compreensão do professor de arte, a BNCC não explica o diálogo entre as linguagens artísticas, dificultando a ação dos professores e, consequentemente, a dos psicopedagogos. A BNCC não expõe a integração das linguagens artísticas e leva em conta que os alunos possuem um conhecimento prévio. Isso pode dificultar o entendimento do professor e do psicopedagogo, considerando que a formação desses profissionais não integra todas as formações em Arte (TOLENTINO; MORENO, 2019, p. 27). 
Das diversas estéticas, movimentos culturais e fenômenos intrínsecos às Artes Visuais, a subcultura Steampunk chama a atenção, por sua tendência ao hibridismo espaciotemporal. Como sugerido no início deste trabalho, a estética do Steampunk, representada na Figura 1, repercute na moda, nos quadrinhos, nos livros, nos filmes... e mais recentemente, nas séries de streaming, webséries, fanfics e demais produções do ambiente digital.

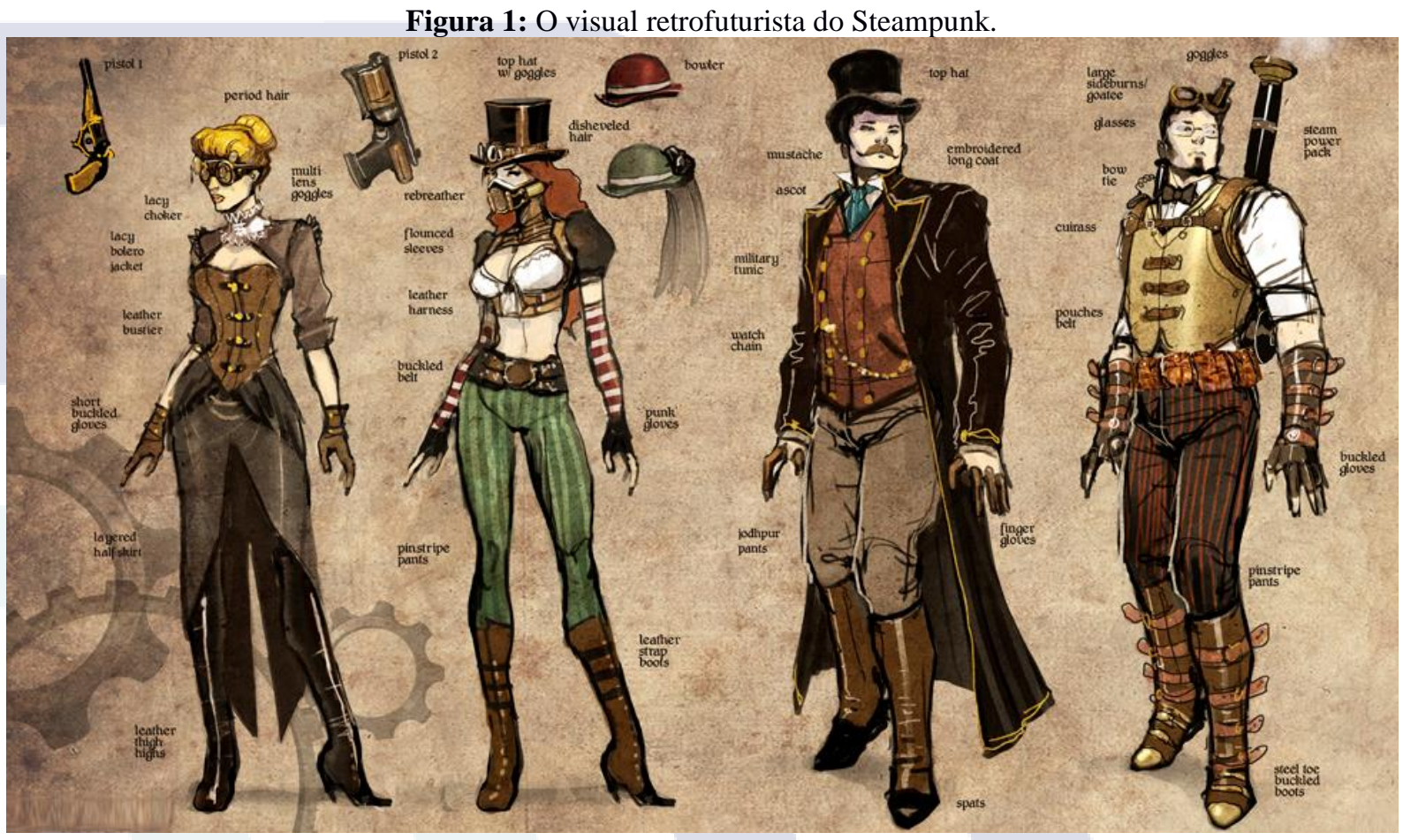

Fonte: Maurey (2015, p. 1).

Considerando as fontes documentais, o Steampunk costuma remeter à "era vitoriana, período britânico do governo da Rainha Vitória (1837-1901), quando o vapor era o principal meio de produção" (MAUREY, 2015, on-line). A autora complementa que, devido ao vapor, "houve avanços tecnológicos e criações incríveis para a época, como robôs a vapor, diligências turbinadas, além de cientistas ‘loucos' e por aí vai” (MAUREY, 2015, on-line).

Haja vista, portanto, a relevância interdisciplinar do Steampunk enquanto objeto de interesse das Artes Visuais, propõe-se uma revisão sistemática sobre os trabalhos científicoacadêmicos publicados em território nacional sobre o referido movimento.

\section{METODOLOGIA}

Para analisarmos as pesquisas acadêmicas sobre Steampunk, objeto de estudo deste trabalho, é preciso localizá-las. Uma busca eletrônica, em qualquer ferramenta própria para essa finalidade, resultaria em milhares de páginas na internet, como sites profissionais, blogs 
pessoais, fóruns temáticos e grupos em redes sociais. Entretanto, visando à necessidade de concentrar as leituras em textos confiáveis, recorremos à revisão sistemática, que fundamenta este trabalho.

Pensando na fundamentação teórico-metodológica, a revisão sistemática "foi desenvolvida como um método específico para identificar e sintetizar evidências de pesquisa" (VICTOR, 2008, p. 1, tradução livre). Em outras palavras, "é uma metodologia rigorosa proposta para: identificar os estudos sobre um tema em questão, aplicando métodos explícitos e sistematizados de busca [...]" (DE-LA-TORRE-UGARTE-GUANILO; TAKAHASHI; BERTOLOZZI, 2011, p. 1261).

Como objetivos, a revisão sistemática "objetiva responder a uma pergunta claramente formulada, utilizando métodos sistemáticos e explícitos para identificar, selecionar e avaliar as pesquisas relevantes, coletar e analisar dados de estudos incluídos na revisão" (CORDEIRO; OLIVEIRA; RENTERÍA; GUIMARÃES, 2007, p. 429). Isto é, “as revisões sistemáticas nos permitem incorporar um espectro maior de resultados relevantes, ao invés de limitar as nossas conclusões à leitura de somente alguns artigos” (SAMPAIO; MANCINI, 2007, p. 84).

A escolha por esse método considerou o fato de que esse tipo de revisão "permite identificar lacunas na pesquisa, ou seja, destacam as áreas em que a qualidade ou quantidade de evidências científicas disponíveis ainda é insuficiente" (ARAUJO ALONSO, 2011, p. 1, tradução livre). Além disso, "esse recurso envolve a aplicação de estratégias científicas, com a finalidade de limitar vieses, congrega, avalia criticamente e sintetiza todos os estudos relevantes que respondem a uma pergunta clínica específica" (GALVÃO; SAWADA; TREVIZAN, 2004, p. 550).

Para que se realize esse tipo de análise, é preciso identificar:

[...] quem está fazendo a pergunta e o que fará com as respostas; o que a revisão fará e quais são suas suposições subjacentes; estabelecer os critérios usados para selecionar estudos; projetar e executar uma estratégia de pesquisa para encontrar fontes; verificar quais estudos são relevantes e descartando aqueles que não são; coletar informações para mapeamento, garantia de qualidade e resultados do estudo; descrever a natureza do campo de pesquisa definido pelos critérios de inclusão; julgar a relevância, utilidade e qualidade dos estudos; reunir as conclusões de diferentes estudos para responder à pergunta da revisão; descrever como a revisão foi realizada, suas descobertas e implicações para futuras decisões" (GOUGH; OLIVER; THOMAS, 2013, p. 11, tradução livre).

Ou seja, é necessário um "planejamento da revisão (identificação da necessidade de uma revisão; desenvolvimento de um protocolo de revisão)" (KITCHENHAM, 2004, p. 3, tradução 
livre), para posterior "realização da revisão (identificação da pesquisa; seleção de estudos primários; avaliação da qualidade do estudo; extração e monitoramento de dados; síntese de dados) e relato da revisão" (KITCHENHAM, 2004, p. 3, tradução livre). Suportada por tais fundamentações teórico-metodológicas, esta pesquisa adotou um criterioso método de abordagem quantitativa e, posteriormente, qualitativa.

Como procedimento metodológico para realização dessa coleta, inicialmente delimitamos a pergunta responsável por nortear a pesquisa exploratória: como compreender o Steampunk? Em segunda etapa, definimos as bases de busca utilizadas para mapear as produções intelectuais que nos ajudassem a responder à pergunta.

Optamos pela pesquisa de modo on-line devido à amplitude dos materiais disponíveis (relativamente maior do que os de uma biblioteca física) e devido à necessidade de distanciamento social implicado pela pandemia COVID-19. Optamos, ainda, pelo uso Google Acadêmico por ser um dos indexadores mais utilizados para os periódicos científicos e editoras acadêmicas da área de Humanidades.

Para a terceira etapa, realizamos a busca eletrônica com a palavra "Steampunk" para averiguar os resultados. Selecionamos os filtros "pesquisar páginas em português" e "a qualquer momento", mas excluímos citações e patentes (recursos de filtragem do próprio software).

Devido à extensão limitada de um artigo científico, focamos nosso interesse nas publicações mais bem recebidas pela comunidade acadêmica, seja pela quantidade de citações ou pelo volume de acessos. Para isso, confiamos nos dados métricos do próprio Google Acadêmico e restringimos a coleta aos dez trabalhos considerados mais relevantes.

\section{RESULTADOS E DISCUSSÃO}

Os resultados quantitativos, considerando as dez publicações mais relevantes segundo o Google Acadêmico, reuniram três livros e sete artigos, de acordo com o quadro 1:

Quadro 1: Produções intelectuais sobre o Steampunk.

\begin{tabular}{|l|c|c|}
\hline TÍTULO DO TRABALHO & AUTOR(ES) & LINK \\
\hline $\begin{array}{l}\text { Steampunk: as transgressões } \\
\text { temporais negociadas de uma } \\
\text { cultura retrofuturista }\end{array}$ & Everly Pegoraro & $\underline{\text { https://tinyurl.com/y5kvmn9q }}$ \\
\hline $\begin{array}{l}\text { No compasso do tempo } \\
\text { steampunk }\end{array}$ & Everly Pegoraro & $\underline{\text { https://tinyurl.com/y32rb8xl }}$ \\
\hline
\end{tabular}




\begin{tabular}{|l|l|l|}
\hline $\begin{array}{l}\text { Retrofuturismo, espaço e corpo- } \\
\text { mídia: steampunk e a memória } \\
\text { do futuro }\end{array}$ & $\begin{array}{l}\text { Mônica R. F. Nunes; } \\
\text { Marco A. Bin }\end{array}$ & $\underline{\text { https://tinyurl.com/y38pkqac }}$ \\
\hline $\begin{array}{l}\text { Retrofuturismo e visualidade } \\
\text { steampunk no brasil }\end{array}$ & Everly Pegoraro & $\underline{\text { https://tinyurl.com/yy5sghne }}$ \\
\hline $\begin{array}{l}\text { O steampunk: uma máquina } \\
\text { literária de reciclar o passado }\end{array}$ & $\begin{array}{l}\text { Jean-Jacques Girardot } \\
\text { Fabrice Méreste }\end{array}$ & $\underline{\text { https://tinyurl.com/yxa7a2ay }}$ \\
\hline $\begin{array}{l}\text { Vaporpunk: relatos steampunk } \\
\text { publicados sob as ordens das } \\
\text { suas majestades }\end{array}$ & $\begin{array}{l}\text { Gerson Lodi-Ribeiro; } \\
\text { Luís F. Silva }\end{array}$ & $\underline{\text { https://tinyurl.com/y5zmhzh7 }}$ \\
\hline $\begin{array}{l}\text { No compasso do tempo } \\
\text { Steampunk: A visualidade de } \\
\text { uma cultura urbana retrofuturista }\end{array}$ & Everly Pegoraro & $\underline{\text { https://tinyurl.com/yxqm6fel }}$ \\
\hline $\begin{array}{l}\text { Performances, fabricos e } \\
\text { artesanias nas cenas cosplay e } \\
\text { steampunk }\end{array}$ & Mônica R. F. Nunes & $\underline{\text { https://tinyurl.com/yyoos4tq }}$ \\
\hline $\begin{array}{l}\text { Cinema retrofuturista } \\
\text { steampunk: possíveis origens de } \\
\text { um subgênero literário }\end{array}$ & Jayme S. Chaves & $\underline{\text { https://tinyurl.com/y2jhhkef }}$ \\
\hline $\begin{array}{l}\text { Espaço urbano e teatralidades } \\
\text { nas cenas medievalista, vitoriana } \\
\text { e steampunk }\end{array}$ & $\begin{array}{l}\text { Mônica R. F. Nunes; } \\
\text { Marco A. Bin }\end{array}$ & $\underline{\text { thyurl.com/yxf3tczr }}$ \\
\hline
\end{tabular}

Fonte: Elaboração própria, com base em resultado do Google Acadêmico.

A coleta de dados apontou uma predominância de dois autores: Everly Pegoraro (2012; 2014; 2015) e Mônica Rebecca Ferrari Nunes (2016), também em coautoria com Marco Antônio Bin (2017a; 2017b). Por esse motivo, as discussões giram em torno desses trabalhos, que parecem ser consagrados - ou estar em processo de consagração - dentro dos estudos de Steampunk.

Formado pela união das palavras "steam" (vapor) e "punk" (cultura demarcada por suas ideias revolucionárias), o Steampunk, mais do que estilo ou movimento artístico, vem sendo considerado um tipo de (sub)cultura. De acordo com Pegoraro (2012, p. 390), “o steampunk caracteriza-se como uma cultura urbana juvenil que ressignifica os costumes vitorianos, permeando-os com discursos tecnológicos e futuristas". Para a autora, a união de aspectos do passado mesclados com visuais do futuro tende a "explorar os limites e as tensões entre a 


\section{STEAMPUNK: UM ESTUDO SOBRE AS ARTES VISUAIS E SUAS INFLUÊNCIAS}

racionalidade e a alienação provenientes dos avanços da tecnologia" (PEGORARO, 2012, p. 393).

A respeito das origens desse movimento, Pegoraro (2015, on-line) registra que "o steampunk herda características de diferentes períodos da ficção científica e do próprio cyberpunk" e esclarece: "Da conhecida Época Dourada (Golden Age), entre meados de 1930 e 1950, as histórias assemelham-se na tentativa de atingir a imortalidade entre homem e máquina". A autora também fala da influência da Nova Onda (New Wave), entre os anos de 1970 e 1980, para o Steampunk: “As temáticas problematizam as relações de poder, as angústias existenciais, as fronteiras da realidade e os elementos constitutivos do ser humano" (PEGORARO, 2015, on-line).

Ainda no que concerne às origens, Nunes e Bin (2017a, p. 2) endossam: "gênero de ficção científica, nascido ao final dos anos 1980, o steampunk é inspirado na literatura do século XIX, especialmente nas aventuras de Júlio Verne e H. G. A. Wells, entre outros autores do período". Sobre o termo em si, os autores explicam que foi "o estadunidense Kevin Wayne Jeter quem escreve duas obras [Morlock Night e Infernal Devices] que configuram o novo gênero, [...] criando viajantes do tempo, máquinas poderosas capazes de voltar ao século XIX para inúmeras aventuras" (NUNES; BIN, 2017a, p. 2).

No tocante à relação entre o Steampunk, as artes e a mídia, Nunes (2016, p. 80) aponta que "da literatura de Júlio Verne ao cinema, passando pelo RPG (abreviação de role playing game, jogo de interpretação de papeis), pelos games, o steampunk é um visual que faz do corpo um corpo mídia". Na explicação da autora, trata-se do "corpo em sua gestualidade, vocalidade e toda sua expressão criando vinculações comunicacionais" (NUNES, 2016, p. 80).

Em diálogo indireto com essa afirmação, Pegoraro (2014, p. 90) pontua que "fotografias, ilustrações, filmes, quadrinhos fornecem informação visual para a criação de roupas, acessórios, arte e maquinários dos adeptos, conhecidos como steamers". Ainda para a autora, "as performances do retrofuturismo em suas variadas possibilidades [...] apontam que as críticas da juventude contemporânea misturam questionamentos, entretenimento e hedonismo" (PEGORARO, 2014, p. 96).

Explorando as influências do Steampunk para a concepção de novas produções no âmbito das artes literárias e cinematográficas, Nunes e Bin (2017a, p. 28), registram que, no universo dos seguidores do Steampunk, "é comum (re)inventarem personagens da época do vapor, enredos e cenários". Como os autores registram: "Palavras, vestidos, barrocos, tabardos, chapéus, perucas, luvas, espartilhos, escudos participam de uma vasta rede de materialidades 
conectadas a muitas camadas de tempo, memórias, regimes e formas de consumir" (NUNES; BIN, 2017a, p. 29).

\section{CONCLUSÕES}

As Artes Visuais são uma área de estudo que abrangem diversos objetos, autores, movimentos, vertentes e estilos. A pesquisa nesse cenário envolve escolhas que podem ser dirigidas por um interesse pessoal, por uma necessidade social ou por um alinhamento com o campo educacional. Neste trabalho, com o intuito de explorar uma (sub)cultura relevante para as Artes Visuais, concentramos nosso olhar para as questões relacionadas ao Steampunk.

Por meio de uma pesquisa bibliográfica, de caráter quantiqualitativo, pautada na revisão sistemática, observamos que a produção acadêmica brasileira destinada ao tema parece se concentrar em dois autores principais: Everly Pegoraro e Mônica Rebecca Ferrari Nunes - esta, também em coautoria de Marcos Antônio Bin. A leitura desses trabalhos nos auxiliou a entender o que é o gênero, suas origens e como ele pode influenciar as artes literárias e cinematográficas.

Vimos que o Steampunk é um movimento cultural que une alguns aspectos do passado, sobretudo nas vestimentas e nos acessórios, com elementos futurísticos, como invenções e aparatos tecnológicos. Tal movimento teve origem na ficção científica, em subgêneros como o cyberpunk e em períodos como a Era Dourada, entre 1930 e 1950, e a Nova Onda, nos anos 1970 e 1980, propagando um embate na relação entre humano e máquina.

Compreendemos que o Steampunk dependeu da arte literária para se propagar, sobretudo nas obras do francês Júlio Verne e do britânico H. G. A. Wells, sendo consolidado nos livros Morlock Night e Infernal Devices, do estadunidense Kevin Wayne Jeter. No contemporâneo, as características do Steampunk prevalecem na literatura, mas também alcançou outras artes, como a pintura, a ilustração e o cinema, e as mídias, como os jogos eletrônicos, a televisão e a internet.

Por fim, concluímos que a elaboração deste artigo auxiliou no entendimento do Steampunk, em sua relevância para as Artes Visuais e outras produções derivadas ou correlatas a elas. Esperamos que, a partir deste primeiro exercício sobre o gênero, novas pesquisas possam ser realizadas, resultando em futuros trabalhos acadêmicos, sobretudo com aplicações analíticas em objetos de interesse da área.

\section{REFERÊNCIAS}

ARAUJO ALONSO, Miguel. Las revisiones sistemáticas. Medwave, Madrid (Espanha), n. 11,
[s.
p.],
nov.
2011.
Disponível
em: 
https://www.medwave.cl/link.cgi/Medwave/Series/mbe01/5220. Acesso em: 04 abr. 2020. DOI: https://10.5867/medwave.2011.11.5220.

BNCC - Base Nacional Comum Curricular (BNCC). Brasília: Ministério da Educação, 2017. Disponível em: https://bit.ly/3jp0xcz. Acesso em: 20 jul. 2020.

CORDEIRO, Alexander Magno; OLIVEIRA, Glória Maria de; RENTERÍA, Juan Miguel; GUIMARÃES, Carlos Alberto. Revisão sistemática: uma revisão narrativa. Revista do Colégio Brasileiro de Cirurgiões, Rio de Janeiro, v. 34, n. 6, p. 428-431, dez. 2007. Disponível em: http://www.scielo.br/scielo.php?script=sci_arttext\&pid=S0100-

69912007000600012\&lng=en\&nrm=iso. Acesso em: 03 abr. 2020. DOI: https://doi.org/10.1590/S0100-69912007000600012.

DE-LA-TORRE-UGARTE-GUANILO, Mônica Cecilia; TAKAHASHI, Renata Ferreira; BERTOLOZZI, Maria Rita. Revisão sistemática: noções gerais. Revista da Escola de Enfermagem da USP, v. 45, n. 5, p. 1260-1266, out. 2011. Disponível em: https://www.revistas.usp.br/reeusp/article/view/40833. Acesso em: 04 abr. 2020. DOI: https://doi.org/10.1590/S0080-62342011000500033.

GALVÃO, Cristina Maria; SAWADA, Namie Okino; TREVIZAN, Maria Auxiliadora. Revisão sistemática: recurso que proporciona a incorporação das evidências na prática da enfermagem. Revista Latino-Americana de Enfermagem, Ribeirão Preto, v. 12, n. 3, p. 549556, jun. 2004. Disponível em: http://www.scielo.br/scielo.php?script=sci_arttext\&pid=S010411692004000300014\&lng=en\&nrm=iso. Acesso em: 04 abr. 2020. DOI: https://doi.org/10.1590/S0104-11692004000300014.

GOUGH, David; OLIVER, Sandy; THOMAS, James. Learning from research: systematic reviews for informing policy decisions: a quick guide. London: Nestadez, 2013. (Alliance for Useful Evidence). Disponível em: http://www.alliance4usefulevidence.org/assets/AllianceFUE-reviews-booklet-3.pdf. Acesso em: 04 abr. 2020.

KITCHENHAM, Barbara. Procedures for Performing Systematic Reviews. Relatório Técnico - Grupo de Engenharia de Software, Departamento de Ciência da Computação, Keele University, Staffordshire (Reino Unido); Engenharia Empírica de Software, National ICT Australia Ltda., Sydney (Austrália), 2004. Disponível em: http://www.inf.ufsc.br/ aldo.vw/kitchenham.pdf. Acesso em: 04 abr. 2020.

MAUREY, Vivi. Você sabe o que é steampunk?. Na mesa do editor, 11 fev. 2015. Rocco Jovens Leitores - Site oficial. Disponível em: https://www.rocco.com.br/voce-sabe-o-que-esteampunk/. Acesso em: 26 set. 2020.

NUNES, Mônica Rebecca Ferrari. Performances, fabricos e artesanias nas cenas cosplay e steampunk. Diálogo com a Economia Criativa. São Paulo, v. 1, n. 1, p. 75-85, 2016. Disponível em: http://dialogo.espm.br/index.php/revistadcec-rj/article/view/37. Acesso em: 26 set. 2020. DOI: http://dx.doi.org/10.22398/2525-2828.1175-85.

NUNES, Mônica Rebecca Ferrari; BIN, Marco Antônio. Espaço urbano e teatralidades nas cenas medievalista, vitoriana e steampunk. Comunicação Midiática. Bauru, v. 12, n. 3, p. 25 39, 2017 a.

Disponível

em: 
https://www2.faac.unesp.br/comunicacaomidiatica/index.php/CM/article/view/26. Acesso em: 26 set. 2020.

NUNES, Mônica Rebecca Ferrari; BIN, Marco Antônio. Retrofuturismo, espaço e corpo-mídia: steampunk e a memória do futuro. Revista FAMECOS. Rio Grande do Sul, v. 25, n. 2, p.1-21, $2017 b$. https://revistaseletronicas.pucrs.br/ojs/index.php/revistafamecos/article/view/29017/0. Acesso em: 26 set. 2020. DOI: http://dx.doi.org/10.15448/1980-3729.2018.2.29017.

PEGORARO, Everly. No compasso do tempo steampunk: o retrofuturismo no contexto brasileiro. Jundiaí: Paco, 2015.2 Disponível em: https://books.google.com.br/books?id=uCiSDgAAQBAJ. Acesso em: 26 set. 2020.

PEGORARO, Everly. Retrofuturismo e visualidade steampunk no Brasil. ALAIC - Revista Latinoamericana de Ciencias de la Comunicación. São Paulo, v. 11, n. 20, p. 88-96, 2014. Disponível em: http://revista.pubalaic.org/index.php/alaic/article/view/494/316. Acesso em: 26 set. 2020.

PEGORARO, Everly. Steampunk: as transgressões temporais negociadas de uma cultura retrofuturista. Cadernos de Comunicação. Santa Maria, v. 16, n. 2, p. 389-400, 2012. Disponível em: https://periodicos.ufsm.br/ccomunicacao/article/view/8236. Acesso em: 26 set. 2020.

PIMENTEL, Lucia Gouvêa; MAGALHÃES, Ana Del Tabor Vasconcelos. Docência em Arte no contexto da BNCC: é preciso reinventar o ensino/aprendizagem em Arte? Revista GEARTE, Porto Alegre, v. 5, n. 2, p. 220-231, maio/ago. 2018. Disponível em: https://www.seer.ufrgs.br/gearte/article/view/83234/49626. Acesso em: 12 nov. 2020.

SAMPAIO, R. F.; MANCINI, M. C. Estudos de revisão sistemática: um guia para síntese criteriosa da evidência científica. Revista Brasileira de Fisioterapia, São Carlos, v. 11, n. 1, p. 83-89, fev. 2007. Disponível em: http://www.scielo.br/scielo.php?script=sci_arttext\&pid=S141335552007000100013\&lng=en\&nrm=iso. Acesso em: 03 abr. 2020. DOI: https://doi.org/10.1590/S1413-35552007000100013.

TOLENTINO, Igor Vieira E Sá; MORENO, Alessandra Dominiquelli. Artes na BNCC: reflexões psicopedagógicas. Cadernos de Educação, v. 18, n. 37, 2019. Disponível em: https://www.metodista.br/revistas/revistasims/index.php/cadernosdeeducacao/article/view/10012. Acesso em: 12 nov. 2020.

VICTOR, Liz. Systematic reviewing. Social Research Update, Guildford (Surrey, Reino Unido), n. 58, 2008. Disponível em: http://sru.soc.surrey.ac.uk/SRU54.pdf. Acesso em: 04 abr. 2020. 